\title{
Serum Procalcitonin in the Prediction of Severity and Outcome of Acute Pancreatitis
}

\author{
Khan Md. Nazmus Saqeb* \\ DOI: https://doi.org/10.3329/bccj.v9i1.53051
}

\begin{abstract}
:
Background: Different modalities are available for predicting severity and outcome of acute pancreatitis. A single marker with high sensitivity and specificity is yet to be identified.

Aim: This study intends to find out the utility of serum procalcitonin in predicting the severity and outcome of acute pancreatitis.

Methods: 117 patients admitted with acute pancreatitis were included.Clinical parameters and biochemical tests were recorded on admission, on day-3 \& day-5 of admission. CT scan was performed in all patients. Serum procalcitonin was done on admission. Multifactorial scores were calculated using these data. Every patient was followed for identification of organ failure or other complications. Statistical analysis was done with SPSS.

Result: Among 117 patients, 67(57.3\%) were male. Biliary, hypertriglyceridemia, alcohol, malignancy and post-ERCP complications were found as aetiology in 25(21.4\%), 23(19.7\%), 8(6.8\%), 3(2.6\%),2(1.7\%) cases respectively. In $53(45.3 \%)$ cases no definite etiology could be found. 83(70.9\%) patients had mild,15(12.8\%) had moderately severe and 19(16.2\%) had severe acute pancreatitis. 23(19.65\%) patients developed complication, whereas 94 (80.34\%) developed none. The mean serum procalcitonin $(\mathrm{pg} / \mathrm{ml})$ of patients with mild, moderately severe and severe disease was $146 \pm 165.21,1297 \pm 439.44,4361 \pm 1493.55$ respectively. The difference among the groups were statistically significant. Mean serum procalcitonin $(\mathrm{pg} / \mathrm{ml})$ in patientswho developed complications was $3744 \pm 1827.05$ and in those without complication it was 301 559.97.ROC curve evaluating the role of serum procalcitonin in predicting outcome of acute pancreatitis showed AUC of 0.985. A cutoff point of $1131.28 \mathrm{pg} / \mathrm{ml}$ showed highest sensitivity (95.7\%) \& specificity (94.7\%).
\end{abstract}

Conclusion: Serum procalcitonin can be a new promising marker to predict severity and outcome of acute pancreatitis.

Keywords: Serum procalcitonin (PCT), Predictor, Severity, Outcome, Acute pancreatitis.

\section{Introduction}

Acute pancreatitis accounts for 3\% of all cases of abdominal pain admitted to hospital ${ }^{1}$. The incidence of acute pancreatitis appears to be increasing ${ }^{2}$. As the population is becoming increasingly overweight, the incidence of gallstones, the most common cause of acute pancreatitis, is rising. Whereas gallstones and alcohol appear to be the cause of acute pancreatitis in the majority of cases, many other conditions like hypertriglyceridemia predispose to acute pancreatitis to varying degrees ${ }^{3}$.About $80 \%$ of all cases are mild and have a favorable outcome. Of the rest $20 \%$ of patients with severe disease, almost all (98\%) die within the first week, usually from multiorgan failure. After this time the majority of deaths result from sepsis, especially that complicating infected necrosis. On admission it is possible to predict patients at risk of this complication ${ }^{1}$.

\footnotetext{
*Corresponding Author:

Dr. Khan Md. Nazmus Saqeb

Assistant Professor

Dept. of Gastrointestinal, Hepatobiliary\& Pancreatic diseases

Jahurul Islam Medical College \& Hospital

Bajitpur, Kishoreganj, Bangladesh.

Mail: drsaqebk59@gmail.com

Phone: +8801715248062

ORCID ID: https://orcid.org/0000-0002-8080-947X
}

Predicting severity of pancreatitis early in the course of disease is critical to maximize therapy and to prevent and minimize organ dysfunction and complications. Unfortunately, the management of patients with acute pancreatitis is complicated by the inability to distinguish mild from severe disease during the early stages ${ }^{3}$.Severe acute pancreatitis has a poor prognosis and early prediction of the severity helps us in taking appropriate steps to halt the disease progression and to reduce development of complications. Several predictors (biochemical parameters, clinico-biochemical scores and radiological scores) have been used to predict the severity of acute pancreatitis. But a simple, inexpensive, routinely available and highly accurate predictor is however not yet available.Procalcitonin (PCT) is a 116-amino acid propeptide of calcitonin with a molecular weight of $13 \mathrm{kDa}^{4}$. It has been introduced as an early marker of severe infection and inflammation ${ }^{5}$. Serum procalcitonin may be very useful in the early prediction of severity of acute pancreatitis and can guide us to initiate effective management before the development of complications. Several studies have been conducted to establish its role in the early prediction of severity of acute pancreatitis. But no such study is done in our country till now. This study aims at establishing the role of serum procalcitonin in the prediction of severity and outcome of acute pancreatitis. 


\section{Methods}

This prospective and observational study was done in the department of Gastrointestinal, Hepatobiliary and Pancreatic Disorders (GHPD), BIRDEM General Hospital, Dhaka, Bangladesh from July, 2015 to February, 2017. Patients aged more than 18 years, admitted with abdominal pain and fulfilling the diagnostic criteria of acute pancreatitis by clinical history, physical examination, biochemical tests and different imaging modalities were included in this study. Patients attending after 72 hours after the onset of abdominal pain, patients having chronic pancreatitis, chronic kidney disease, serious co-morbid conditions like COPD, heart failure and patients suffering from severe infection or inflammation of any other organ system were excluded from the study. Patients unwilling to give voluntary consent to participate in the study were also excluded. Consecutive type of non-probability sampling technique was applied to enroll the patients. Prior to the commencement of this study, the research protocol was approved by theEthical Review Committee (ERC) of the Diabetic Association of Bangladesh (BADAS).The aims and objective of the study along with its procedure, alternative diagnostic methods, risk and benefits were explained to the patients in easily understandable local language and then informed consent was taken from each patient. A predesigned structured questionnaire was used for recording all the data. To detect etiology of acute pancreatitis, liver function test, fasting lipid profile, USG of abdomen were done in all cases. Demographic data like age, sex, BMI; clinical data like presence of abdominal pain, severity and radiation of abdominal pain, abdominal lump, anemia, fever, GCS score, vital parameters were recorded. Laboratory data like hemoglobin, white blood cell count, platelet count, FBS, HbA1c, blood urea, BUN, serum creatinine, serum amylase, serum lipase, serum procalcitonin, serum bilirubin, serum albumin, AST, ALT, alkaline phosphatase, serum LDH, fasting lipid profile, ABG, CA 19.9, USG and CT scan of upper abdomen findings were recorded. Laboratory tests were done on admission and $\mathrm{CBC}$, serum creatinine, $\mathrm{BUN}$, ABG were repeated on day 3 and on day 5 of admission to follow up the patient. Computed tomography (CT) scan was performed in all patients after 72 hours of admission for detection of the development of fluid collections, the extent of inflammation, and necrotic changes. Serum procalcitonin levels were done on admission. Glasgow score, Ranson's score and BISAP score was calculated using the data available within the first 24 hours after admission. Attacks of acute pancreatitis were classified as mild, moderately severe and severe according to revised Atlanta criteria and with the help of modified Marshall scoring system for organ failure. Every patient was followed regularly for identification of organ failure or any other complication.

Statistical analyses were carried out by using the Statistical Package for Social Sciences version 22.0 for Windows (SPSS Inc., Chicago, Illinois, USA). Continuous variables were expressed as mean, standard deviation, and categorical variables as frequencies and percentages. The differences between groups were analyzed by unpaired t-test, chi-square $\left(\mathrm{X}^{2}\right)$ test, and ANOVA test. Correlation between variables was measured by Spearman correlation coefficient test. A p-value $<0.05$ was considered as significant.

\section{Result}

A prospective observational study was carried out to evaluate the role of serum procalcitonin in predicting severity and outcome of acute pancreatitis. Total 117 patients with acute pancreatitis, who fulfilled the inclusion criteria, were included in this study. Among the patients, 67(57.3\%) patients were male and 50(42.73\%) patients were female (Table I). Mean age of the study population was $47.99 \pm 15.90($ mean \pm SD) with minimum age 18 years and maximum age 95 years.

In this study $82(70.1 \%)$ patients were diabetic. Out of 117 patients, 36(30.8\%) were smoker and $10(8.5 \%)$ were alcoholic. 55(47\%) patients were overweight and $12(10.3 \%)$ patients were obese. Mean BMI was 25.36 \pm 3.4 . Mean hematocrit on admission was $37.23 \pm 4.80$. Mean blood urea nitrogen was $17.40 \pm 9.61$ and mean $\mathrm{HbA}_{1 \mathrm{c}}$ was $7.97 \pm 1.70$. Average duration of hospital stay was $8.04 \pm 4.26$ days.In this study, $25(21.4 \%)$ cases were gall stone pancreatitis, $23(19.7 \%)$ cases were due to hyper triglyceridaemia, $8(6.8 \%)$ cases were due to alcohol, $3(2.6 \%)$ cases were due to malignancy, $2(1.7 \%)$ cases due to post ERCP complications, $2(1.7 \%)$ cases were due to gall stones and hypertriglyceridemia and $1(0.9 \%)$ cases were due to hyper triglyceridaemia and alcohol.

In 53(45.3\%) cases no definite etiology could be found. Out of 117 patients $83(70.9 \%)$ had mild acute pancreatitis according to revised Atlanta criteria, 15(12.8\%) patients had moderately severe acute pancreatitis and 19(16.2\%) patients had severe acute pancreatitis. This study showed that, 94 (80.34\%) patients did not develop any kind of complications from acute pancreatitis, on the other hand 23 (19.65\%) patients developed complications. The mean serum PCT of patients with mild disease was $146 \pm 165.21$ (mean \pm SD) $\mathrm{pg} / \mathrm{ml}$, in patients with moderately severe disease was $1297 \pm 439.44$ (mean $\pm \mathrm{SD}$ ) $\mathrm{pg} / \mathrm{ml}$ and in severe acute pancreatitis it was $4361 \pm 1493.55($ mean \pm SD) $p g / m l$. The difference among the groups were statistically significant (Table II).

Thus, serum PCT could predict disease severity early in the course of disease successfully. Mean serum PCT in patients with acute pancreatitis who developed complications was $3744 \pm 1827.05($ mean \pm SD) $\mathrm{pg} / \mathrm{ml}$ and in those without complication it was $301 \pm 559.97$ (mean \pm SD) $\mathrm{pg} / \mathrm{ml}$. The difference between the two groups was statistically significant (Table III). ROC curve evaluating the role of serum PCT in predicting outcome of acute pancreatitis showed AUC of 0.985 (Figure 1). A cut off point of $1131.28 \mathrm{pg} / \mathrm{ml}$ showed highest sensitivity (95.7\%) \& specificity (94.7\%) (Table IV). 
Table I: Demographic, clinical and biochemical characteristics of the study population $(n=117)$.

\begin{tabular}{lr}
\hline Parameters & Result \\
\hline Age (years) & $47.99 \pm 15.90$ \\
Sex (Male) & $67(57.3)$ \\
Contributing factor & $36(30.8)$ \\
$\quad$ Smoking & $10(8.5)$ \\
$\quad$ Alcohol & $93(79.5)$ \\
$\quad$ Tea/ coffee & $3(2.6)$ \\
$\quad$ Oral contraceptives & $82(70.1)$ \\
$\quad$ Diabetes mellitus & $25.36 \pm 3.4$ \\
Body Mass Index & \\
Clinical features & $117(100.0)$ \\
$\quad$ Abdominal pain & $109(93.2)$ \\
$\quad$ Nausea and / or vomiting & $24(20.5)$ \\
Fever & $8.04 \pm 4.26$ \\
Duration of hospital stay & $37.23 \pm 4.80$ \\
Hematocrit & $17.40 \pm 9.61$ \\
Blood urea nitrogen & $60.61 \pm 81.2$ \\
\hline C-reactive protein &
\end{tabular}

Values are expressed as mean \pm SD. Values within the bracket are expressed as percentage.

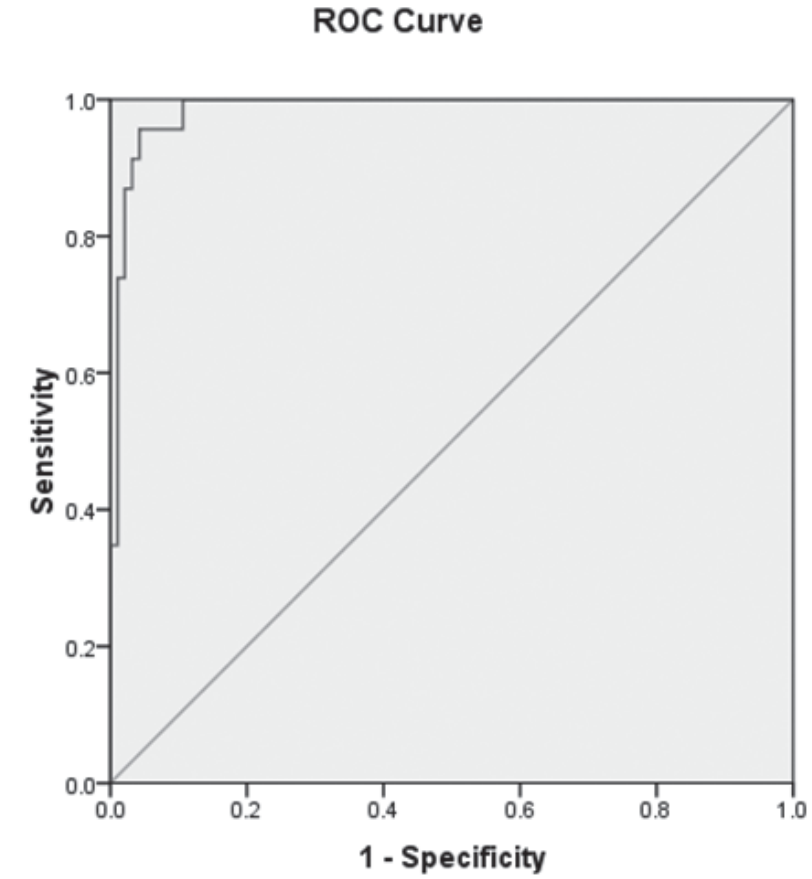

Figure 1: ROC curve showing test accuracy of serum procalcitonin in the prediction of outcome of acute pancreatitis $(\mathrm{AUC}=0.985, \mathrm{p}<0.001)$.

Table II: Association of serum procalcitonin (PCT) with severity of acute pancreatitis (based on revised Atlanta criteria) ( $\mathrm{n}=117)$.

\begin{tabular}{lccc}
\hline Severity of acute pancreatitis & n (\%) & $\begin{array}{c}\text { Serum PCT (pg/ml) } \\
\text { (Mean } \pm \text { SD) }\end{array}$ & p value \\
\hline Mild & $83(70.94)$ & $146.37 \pm 165.21$ & $<0.001$ \\
Moderately severe & $15(12.82)$ & $1297.24 \pm 439.44$ & \\
Severe & $19(16.24)$ & $4361.93 \pm 1493.55$ & \\
\hline
\end{tabular}

Table III: Association between serum procalcitonin (PCT) and outcome of acute pancreatitis ( $\mathrm{n}=117)$.

\begin{tabular}{lccc}
\hline Outcome of acute pancreatitis & $\mathbf{n}(\%)$ & $\begin{array}{c}\text { Serum PCT (pg/ml) } \\
\text { (Mean } \pm \text { SD) }\end{array}$ & p value \\
\hline Developed no complication & $94(80.34)$ & $301.76 \pm 559.97$ & $<0.001$ \\
Developed complication & $23(19.65)$ & $3744.32 \pm 1827.05$ & \\
\hline
\end{tabular}


Bangladesh Crit Care J March 2021; 9 (1): 16-21

Table IV: Evaluation of different cut off points of serum procalcitonin as a predictor of outcome of acute pancreatitis ( $\mathrm{n}=117)$.

\begin{tabular}{lcccc}
\hline Cutoff points for Serum procalcitonin & Sensitivity & Specificity & PPV $^{*}$ & NPV $^{* *}$ \\
\hline 933.03 & 95.7 & 89.4 & 68.8 & 98.8 \\
1005.15 & 95.7 & 92.6 & 75.9 & 98.9 \\
1131.28 & 95.7 & 94.7 & 81.5 & 98.9 \\
1230.29 & 91.3 & 95.7 & 84.0 & 97.8 \\
\hline
\end{tabular}

*Positive predictive value, ${ }^{* *}$ Negative predictive value.

Table V: Performance test of serum procalcitonin in predicting outcome of acute pancreatitis $(\mathrm{n}=117)$

\begin{tabular}{lcccc}
\hline \multicolumn{2}{c}{ Serum procalcitonin $(\mathbf{p g} / \mathbf{m l})$} & Outcome & Total & p-value \\
& With complication & Without complication & & \\
\hline$\geq 1131.28$ & $22(95.7)$ & $5(5.3)$ & $27(23.1)$ & $<0.001$ \\
$<1131.28$ & $1(4.3)$ & $89(94.7)$ & $90(76.9)$ & \\
Total & $23(100.0)$ & $94(100.0)$ & $117(100.0)$ & \\
\hline
\end{tabular}

Table VI: Correlation of serum procalcitonin with Glasgow, Ranson and BISAP score.

\begin{tabular}{lcc}
\hline Marker & r value & p value \\
\hline Serum Procalcitonin & 1.0 & $<0.001$ \\
Glasgow score & 0.653 & $<0.001$ \\
Ranson score & 0.580 & $<0.001$ \\
BISAP score & 0.644 & $<0.001$ \\
\hline
\end{tabular}

Table VII: Correlation among Serum Procalcitonin (PCT), Hematocrit (HCT), CRP and Blood Urea Nitrogen (BUN). $(\mathrm{n}=117)$

\begin{tabular}{lcc}
\hline Marker & r value & p value \\
\hline Serum Procalcitonin & 1.0 & $<0.001$ \\
Hematocrit (HCT) & 0.614 & $<0.001$ \\
CRP & 0.580 & $<0.001$ \\
Blood Urea Nitrogen (BUN) & 0.583 & $<0.001$ \\
\hline
\end{tabular}

\section{Discussion}

A prospective observational study was carried out to evaluate the role of serum procalcitonin in predicting severity and outcome of acute pancreatitis. Total 117 patients with acute pancreatitis, who fulfilled the inclusion criteria, were included in this study. Among the patients, 67(57.3\%) patients were male and 50(42.73\%) patients were female (Table I). Mean age of the study population was $47.99 \pm 15.90$ (mean \pm SD) with minimum age 18 years and maximum age 95 years. A study by Albulushi et al. ${ }^{6}$ found the mean age of acute pancreatitis to be 47 years among which $55 \%$ were male and $45 \%$ were female. The mean age and sex difference of the above study correlate with this study.

In our study $82(70.1 \%)$ patients were diabetic and this can be explained by inclusion of patients from a tertiary level diabetic hospital. Haque $\mathrm{MM}^{7}$, in his study also found that $66.2 \%$ of the patients were diabetic. Out of 117 patients, $36(30.8 \%)$ were smoker and $10(8.5 \%)$ were alcoholic. $55(47 \%)$ patients were overweight and $12(10.3 \%)$ patients were obese. Mean BMI was $25.36 \pm 3.4$. Haque $\mathrm{MM}^{7}$ found that mean BMI was 25.88 \pm 2.95 . Mean hematocrit on admission was $37.23 \pm 4.80$. Mean blood urea nitrogen was $17.40 \pm 9.61$ and mean $\mathrm{HbA}_{1 \mathrm{c}}$ was $7.97 \pm 1.70$. Average duration of hospital stay was $8.04 \pm 4.26$ days. Haque $\mathrm{MM}^{7}$, in his study also found that mean HCT was $32.9 \pm 7.5$, mean BUN was 21.7 7.2, mean $\mathrm{HbA}_{1 \mathrm{c}}$ was $7.8 \pm 1.7$ and average duration of hospital stay was $7.8 \pm 2.5$ days. All of which is almost similar to our study results.

In our study, 25(21.4\%) cases were gall stone pancreatitis, $23(19.7 \%)$ cases were due to hyper triglyceridaemia, $8(6.8 \%)$ cases were due to alcohol, $3(2.6 \%)$ cases were due to malignancy, $2(1.7 \%)$ cases due to post ERCP complications, $2(1.7 \%)$ cases were due to gall stones and hyper triglyceridemia and $1(0.9 \%)$ case was due to hyper triglyceridaemia and alcohol. In 53(45.3\%) cases no definite etiology could be found. Al-Karawi et al. ${ }^{8}$ found that $67.5 \%$ cases of acute pancreatitis were due to biliary cause; alcohol was responsible in $1.8 \%$ of cases and $17 \%$ cases were due to unknown cause. In another study, Chang et al. ${ }^{9}$ found gall stone as etiology in $34.1 \%$ of cases and alcohol in $33.6 \%$ cases and hyper triglyceridaemia in $12.3 \%$ of cases.

High prevalence of hypertriglyceridemia in our study could be 
explained by increased prevalence of DM, obesity and metabolic syndrome among the study population. And the low prevalence of alcohol as etiology of acute pancreatitis could be due to social custom as well as religious belief.

Out of 117 patients $83(70.9 \%)$ had mild acute pancreatitis according to revised Atlanta criteria, $15(12.8 \%)$ patients had moderately severe acute pancreatitis and $19(16.2 \%)$ patients had severe acute pancreatitis. Cho et al. ${ }^{10}$ found $13 \%$ cases as severe acute pancreatitis, $8 \%$ cases as moderately severe and $79 \%$ cases as mild acute pancreatitis in their study which is similar to present study. This study showed that, 94 (80.34\%) patients did not develop any kind of complications from acute pancreatitis, on the other hand $23(19.65 \%)$ patients developed complications. Albulushi et al. ${ }^{6}$ found $32 \%$ patients that developed complication of acute pancreatitis in their study. Haque $\mathrm{MM}^{7}$ in his study found that $17(23.9 \%)$ developed complication whereas 54(76.1\%) developed no complication, which is similar to our study.

The mean serum procalcitonin of patients with mild disease was $146 \pm 165.21$ (mean \pm SD) $\mathrm{pg} / \mathrm{ml}$, in patients with moderately severe disease was $1297 \pm 439.44$ (mean \pm SD) $\mathrm{pg} / \mathrm{ml}$ and in severe acute pancreatitis it was $4361 \pm 1493.55$ (mean \pm SD) $\mathrm{pg} / \mathrm{ml}$. The difference among the groups were statistically significant (Table II; $\mathrm{p}<0.001$ ). Thus, serum procalcitonin could predict disease severity early in the course of disease successfully.Mean serum procalcitonin in patients with acute pancreatitis who developed complications was $3744 \pm 1827.05($ mean \pm SD) $\mathrm{pg} / \mathrm{ml}$ and in those without complication it was $301 \pm 559.97$ (mean \pm SD) $\mathrm{pg} / \mathrm{ml}$. The difference between the two groups was statistically significant (Table III; $p<0.001$ ). ROC curve evaluating the role of serum procalcitonin in predicting outcome of acute pancreatitis showed AUC of 0.985 (Figure 1). A cut off point of 1131.28 $\mathrm{pg} / \mathrm{ml}$ showed highest sensitivity (95.7\%) \& specificity (94.7\%) (Table IV).So, serum procalcitonin could predict outcome of acute pancreatitis successfully very early in the disease.

Mofidi et al. ${ }^{11}$ also found serum procalcitonin to be valuable in predicting severity of acute pancreatitis and the risk of developing infected pancreatic necrosis. The sensitivity and specificity of serum procalcitonin (PCT) for prediction of infected pancreatic necrosis were $80 \%$ and $91 \%$ respectively, when a cutoff PCT level of more than $500 \mathrm{pg} / \mathrm{ml}$ was set. ROC curve analysis showed an AUC of 0.91, which is quite similar to our study.Rau et al. ${ }^{12}$ suggested that monitoring of procalcitonin allows early and reliable assessment of clinically relevant pancreatic infections and overall prognosis in acute pancreatitis. ROC curve analysis showed a PCT level of $\geq 3500 \mathrm{pg} / \mathrm{ml}$ was $93 \%$ sensitive and $88 \%$ specific for the prediction of development of infected necrosis with multiorgan dysfunction syndrome (MODS) or non-survival ( $p$ $<0.01)$.

Bezmarevic et al. ${ }^{13}$ concluded that serum procalcitonin was a good predictor of outcome of acute pancreatitis. According to Spearman ranked correlations, serum procalcitonin, Glasgow score, Ranson score and BISAP score of the patients with acute pancreatitis showed positive correlation with each pair of them (table VI; $\mathrm{p}<0.001$ ). Woo et al. ${ }^{14}$ compared serum procalcitonin with other scoring systems and found similar results. Serum procalcitonin also showed significantly positive correlation with hematocrit (HCT), BUN and CRP levels according to Spearman ranked correlation technique (table VII; $\mathrm{p}<0.001)$.

\section{Conclusion}

This study evaluated the role of serum procalcitonin in predicting severity and outcome of acute pancreatitis. The difference of serum procalcitonin levels between mild, moderately severe and severe acute pancreatitis was statistically significant and it was also higher in patients who developed complications following acute pancreatitis than those without complications. This difference was also statistically significant. ROC curve also showed effectiveness of serum procalcitonin in predicting outcome of acute pancreatitis. So, serum procalcitonin can be a new promising marker to predict severity and outcome of acute pancreatitis.

\section{References}

1. Penman, ID and Lees, CW 2014, 'Alimentary tract and pancreatic disease', in Walker, BR, Colledge, NR, Ralston, SH and Penman, ID (eds), Davidson's Principle and Practice of Medicine, Elsevier, Edinburgh.

2. Frey, CF, Zhou, H, Harvey, DJ and White, RH 2006, 'The incidence and case-fatality rates of acute biliary, alcoholic, and idiopathic pancreatitis in California, 1994-2001', Pancreas, vol. 33, pp. $336-44$.

3. Tenner, S and Steinbergh, WM 2016, 'Acute pancreatitis', in Feldman, M, Friedman, LS and Brandt, LJ (eds), Sleisenger and Fordtran's Gastrointestinal and Liver Disease,pp. 969-993, Elsevier, Philadelphia.

4. Oczenski, W, Fitzgerald, RD and Schwarz, S 1998, 'Procalcitonin: a new parameter for the diagnosis of bacterial infection in the peri-operative period', Eur J Anaesthesiol, vol. 15, pp. 202-9.

5. Oberhoffer, M, Vogelsang, H, Russwurm, S, Hartung, $\mathrm{T}$ and Reinhart, K 1999, 'Outcome prediction by traditional and new markers of inflammation in patients with sepsis' ClinChem Lab Med, vol. 37, pp. 363-8.

6. Albulushi, A, Siddiqi A, Alqarshoubi, I, Aladawi, M, Alkhadhouri, G \&Farhan, H 2014. Pattern of Acute Pancreatitis in a Tertiary Care Center in Oman. Oman Medical Journal, vol. 29, no 5, pp. 358-361.

7. Haque, MM 2016, 'Serum Lipase Amylase Ratio in Predicting Aetiology, Severity and Outcome of Acute Pancreatitis in a Tertiary Care Hospital', MD Thesis, University of Dhaka.

8. Al-Karawi MA, Mohamed AE, Dafala MM, Yasawi MI \& Ghadour ZM. Acute pancreatitis in Saudi patients. Saudi J Gastroenterol 2001;7(1):30-33.

9. Chang $\mathrm{MC}, \mathrm{Su} \mathrm{CH}$, Sun MS, Huang SC, Chiu CT \& Chen MC. Etiology of acute pancreatitis--a multi-center study in Taiwan. Hepatogastroenterology 2003;50(53):1655-7.

10. Cho JH, KimTN, Chung HH \& Kim KH. Comparison of scoring systems in predicting the severity of acute pancreatitis. World J Gastroenterol 2015;21(8):2387-2394. 
11. Mofidi R, Suttie SA, Patil PV, Ogston S and Parks RW. The value of procalcitonin at predicting the severity of acute pancreatitis and development of infected pancreatic necrosis: systematic review. Surgery 2009;146(1):72-81.

12. RauBM, Kemppainen EA, Gumbus AA, Buchler MW, Wegscheider K, Bassi C, PuolakkainenPA and Beger HG. Early Assessment of Pancreatic Infections and Overall Prognosis in Severe Acute Pancreatitis by Procalcitonin (PCT). Ann Surg2007; 245:745-754.

13. Bezmarević M, Kostić Z, Jovanović M, Micković S, Mirković D, Soldatović I, TrifunovićB, Pejović J and Vujanić S. Procalcitonin and BISAP score versus $\mathrm{C}$-reactive protein and APACHE II score in early assessment of severity and outcome of acute pancreatitis. VojnosanitPreg 2012;69(5):425-31.
14. Woo SM, Noh MH, Kim BG, Hsing CT, Han JS, Ryu SH, Seo JM, Yoon HA, Jang JS, Choi SR and Cho JH. Comparison of serum procalcitonin with Ranson, APACHE-II, Glasgow and Balthazar CT severity index scores in predicting severity of acute pancreatitis. Korean J Gastroenterol 2011;58(1):31-7. 